\title{
Hemoglobin level trajectories in the early treatment period are related with survival outcomes in patients with breast cancer
}

\author{
Chia-Lin Lee ${ }^{1,2,3,4}$, Chun-Hao Tsai ${ }^{5,6}$, Dah-Cherng Yeh, Chi-Shy Lin ${ }^{8}$, Yu-Fen Li $^{4}$, \\ Huey-En Tzeng $6,9,10$ \\ ${ }^{1}$ Division of Endocrinology and Metabolism, Department of Internal Medicine, Taichung Veterans General Hospital, Taiwan \\ ${ }^{2}$ Department of Public Health, College of Public Health, China Medical University, Taichung, Taiwan \\ ${ }^{3}$ Department of Medical Research, Taichung Veterans General Hospital, Taiwan \\ ${ }^{4}$ Graduate Institute of Biostatistics, China Medical University, Taichung, Taiwan \\ ${ }^{5}$ Department of Orthopedics, China Medical University Hospital, Taichung, Taiwan \\ ${ }^{6}$ School of Medicine, China Medical University, Taichung, Taiwan \\ ${ }^{7}$ Department of Surgery, Taichung Tzu Chi General Hospital, Taichung, Taiwan \\ ${ }^{8}$ Department of Family Medicine, Taichung Veterans General Hospital, Taiwan \\ ${ }^{9}$ Division of Hematology/Oncology, Department of Medicine, Taichung Veterans General Hospital, Taichung, Taiwan \\ ${ }^{10}$ Breast Cancer Center, Taichung Veterans General Hospital, Taiwan \\ Correspondence to: Yu-Fen Li, email: yufenli@mail.cmu.edu.tw \\ Huey-En Tzeng, email: tzenghueyen@gmail.com
}

Keywords: breast cancer, hemoglobin, survival, trajectory

Received: October 06, $2016 \quad$ Accepted: November 08, 2016

Published: November 29, 2016

\section{ABSTRACT}

Hemoglobin ( $\mathrm{Hb}$ ) levels are reportedly related with treatment outcomes and survival in patients of breast cancer. However, the long-term change in $\mathrm{Hb}$ levels after treatment and the effects of $\mathrm{Hb}$ on survival remain unknown. This retrospective cohort study enrolled 1931 breast cancer patients with pathological stage I-IV between $1 / 1 / 2003$ and $12 / 31 / 2013$. Latent class modeling was used to identify trajectories in monthly $\mathrm{Hb}$ levels over time. The primary endpoint was 10-year cancer-related death. We identified 5 distinct Hb trajectories: persistent anemia $(5.6 \% ; n=109)$, improved anemia $(4.8 \%, n=93)$, mild anemia $(21.0 \%$; $n=406)$, low normal Hb (46.6 \%; $n=899)$, and normal Hb $(21.9 \% ; n=424)$. Compared with the normal-Hb group, trajectories with low $\mathrm{Hb}$ levels had worst 10-year survival. The adjusted hazard ratios were $1.79(95 \% \mathrm{CI}, 0.91-3.53)$ for the improved anemia group, $1.09(95 \% \mathrm{CI}$, 0.68-1.74) for the mild anemia group, 1.06 (95\% CI, 0.71-1.60) for the low normal $\mathrm{Hb}$ group, and 2.19 (95\% CI 1.28-3.75) for the persistent anemia group. Our findings show there are five $\mathrm{Hb}$ level trajectories during breast cancer treatment. The anemia $\mathrm{Hb}$ level trajectory during the first 12 months after treatment reflect the worst cancerrelated 10-year survival in breast cancer patients.

\section{INTRODUCTION}

The incidence of anemia in patients with solid tumors is reportedly $2-78 \%$ [1]. The causes of anemia in cancer patients are multifactorial, including chemotherapy and radiation-induced myelosuppression, bleeding, marrow infiltration by cancer invasion, nutritional deficiencies, and cytokine-mediated anemia. Hemoglobin ( $\mathrm{Hb})$ levels are related with treatment outcomes and survival in patients with various cancers [2-8]. However, there are few studies that have focused on pre-treatment $\mathrm{Hb}$ levels for breast cancer prognosis [9-13]. Moreover, the Hb level might change after treatment (chemotherapy, radiation therapy, or surgery) or with different cancer stages. Therefore, the long-term effects of $\mathrm{Hb}$ on survival after treatment remain unknown.

We hypothesized that multiple $\mathrm{Hb}$ level trajectories exist within different stages of breast cancer, and a lower $\mathrm{Hb}$ level trajectory is associated with poorer long-term survival.

Therefore, the aims of this study were to identify subgroups with similar $\mathrm{Hb}$ level trajectories with different 
Table 1: Baseline characteristics

\begin{tabular}{lc}
\hline Variable & Mean \pm SD or N(\%) \\
\hline Age at diagnosis & \\
$\quad<40$ & $249(12.89)$ \\
$40-49$ & $635(32.88)$ \\
$50-59$ & $598(30.97)$ \\
Over60 & $449(23.25)$ \\
Pathologic stage & \\
1 & $596(30.86)$ \\
2 & $840(43.5)$ \\
3 & $430(22.27)$ \\
4 & $65(3.37)$ \\
ER+ & $1249(65.09)$ \\
PR+ & $1000(52.14)$ \\
ER+ or PR+ & $1334(69.52)$ \\
HER2 & $614(35.66)$ \\
Cell Differentiation & \\
well & \\
moderate & $200(10.36)$ \\
poor & $951(49.25)$ \\
Hb at diagnosis & $780(40.39)$ \\
Chrgery & $12.8 \pm 1.4$ \\
Radiotherapy & $1928(99.9)$ \\
Parity Hx & $1351(70.0)$ \\
\hline & $1064(55.13)$ \\
& $1640(88.60)$ \\
\hline
\end{tabular}

Abbreviations: $\mathrm{ER}+$, estrogen receptor positive. $\mathrm{PR}+$, progesterone receptor positive. $\mathrm{ER}+$ or $\mathrm{PR}+$, estrogen or progesterone receptor positive. HER2, human epidermal growth factor receptor 2 positive.Hb, hemoglobin. $\mathrm{Hx}$, history.

breast cancer stages, to determine the independent association cancer stages level trajectories within a specific treatment time interval and long-term survival, and to assess survival with different cancer stages based on $\mathrm{Hb}$ trajectories.

\section{RESULTS}

\section{Characteristics of patients}

Table 1 summarizes the basic characteristics of the study population. Of the 1931 patients who were enrolled, 256 patients died during the follow up. The mean age of the patients at the time of diagnosis was 52 years; most of the patients were aged 40-49 years (33\%). Primary breast cancer diagnoses occurred at stage II for $43.5 \%$ of the patients, at stage I for $31.0 \%$ of the patients, and at stage III for $22.3 \%$ of the patients. Surgery was the most common treatment for patients following diagnosis (99.9\%), followed by chemotherapy (70.2\%) and radiotherapy $(55.1 \%)$. During the 5 years following the primary treatment, $64.4 \%$ of the cases received hormone therapy.

\section{Trend in Hb changes within one year of treatment}

The mean $\mathrm{Hb}$ level was the highest at the beginning of the 1-year period following treatment and then gradually decreased to $<12.0 \mathrm{mg} / \mathrm{dL}$ at 3 months and returned to $>12.0 \mathrm{mg} / \mathrm{dL}$ at the end of the 1 -year period (Figure 1A). 
A

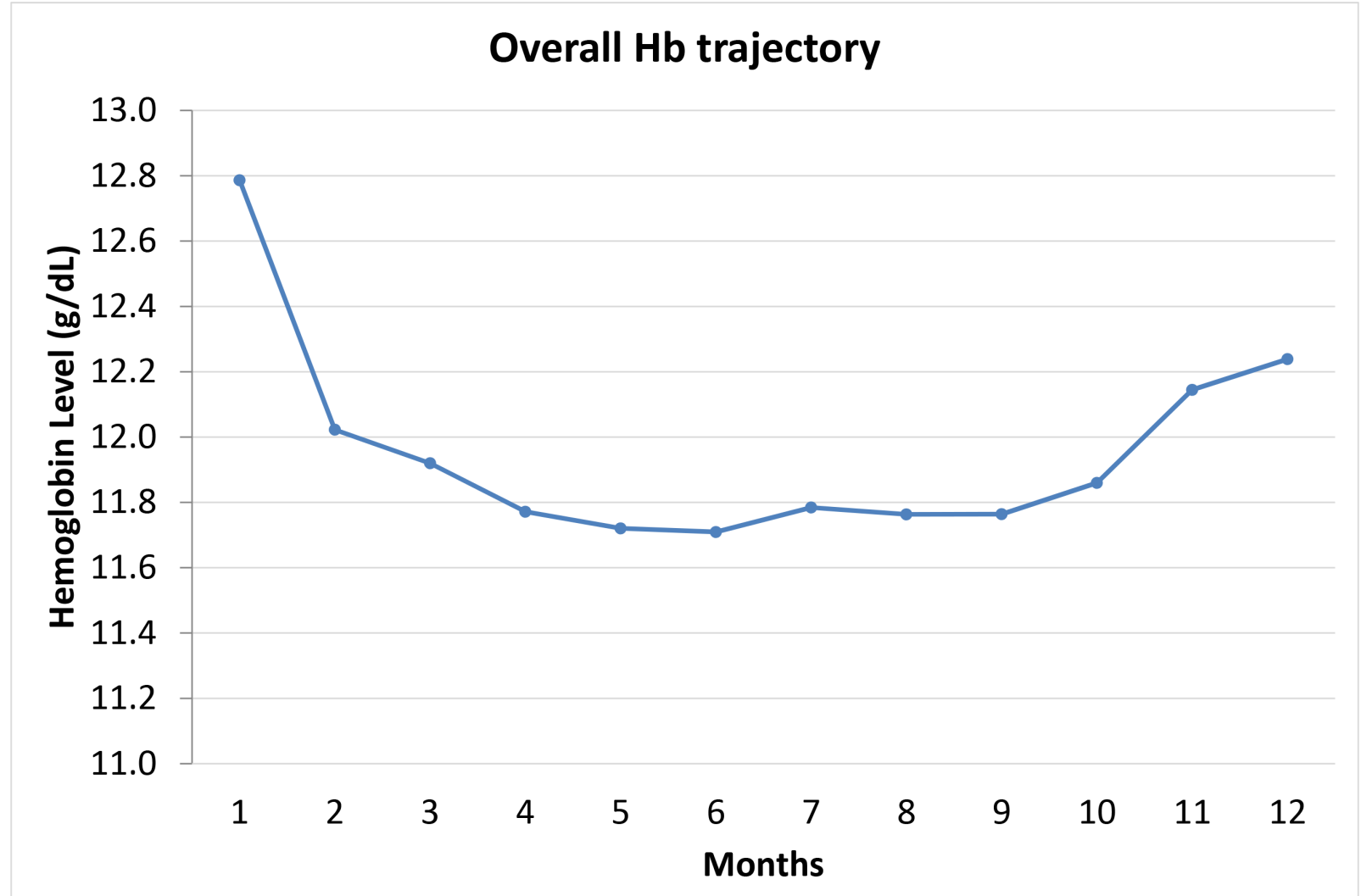

B

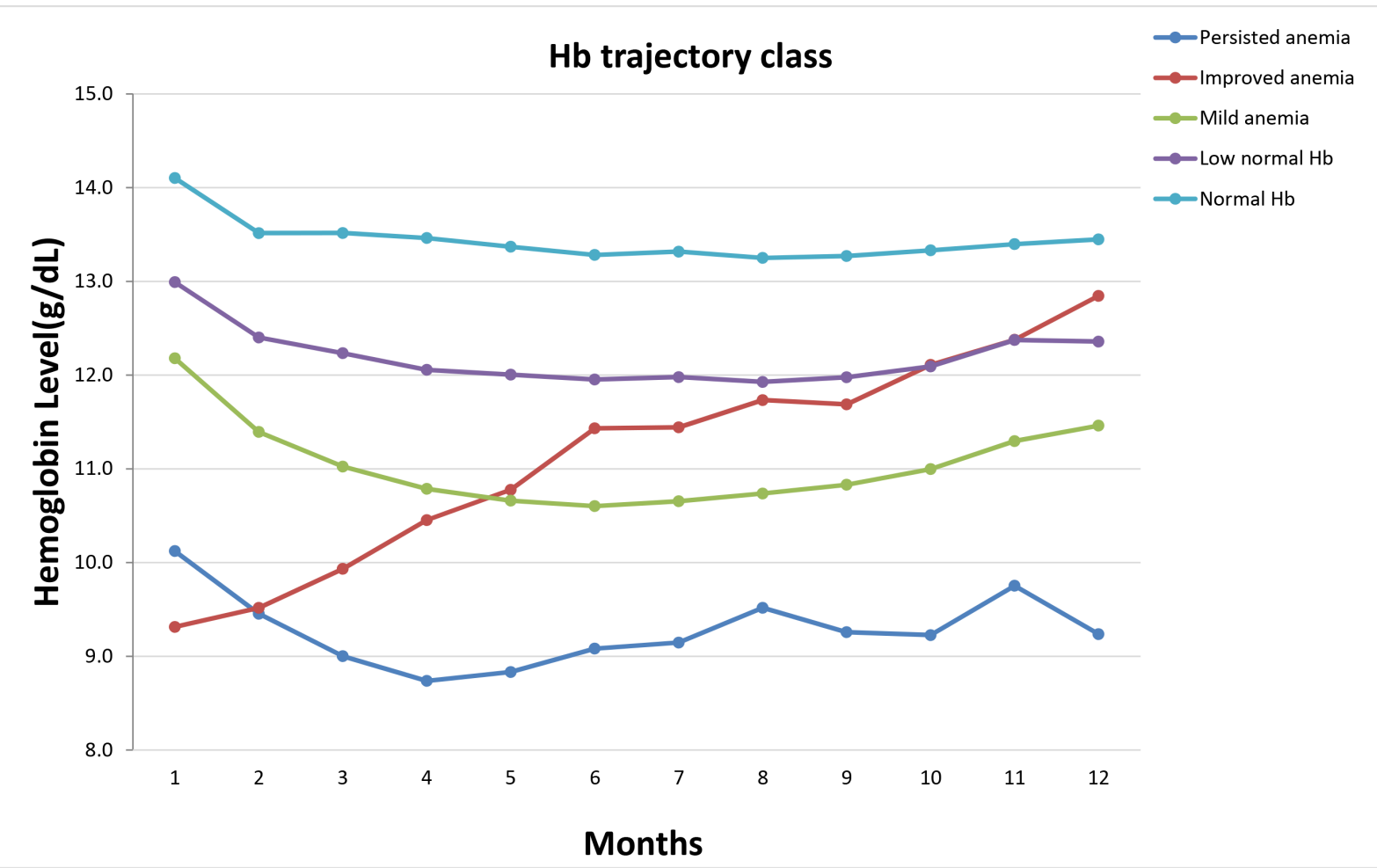

Figure 1: Trajectory of $\mathbf{H b}$ level within the first year of breast cancer. Overall $\mathrm{Hb}$ trajectory (1A) and distinct five Hb trajectories (1B) by group-based trajectory modeling were plotted. 


\section{Changes in different $\mathrm{Hb}$ trajectories}

Using the group-based trajectory modeling, we identified five $\mathrm{Hb}$ trajectories within the 1-year period following treatment (Figure 1B, Table 2, Supplementary Figure S1). There were no differences in cell differentiation grade and parietal history between the trajectories. The normal $\mathrm{Hb}$ group had the highest baseline $\mathrm{Hb}$ level and a higher percentage of pathological stages I and II and was more likely to have a ER/PR(+) status and to have received hormone therapy. A higher proportion of the persistent anemia group had stage III or IV cancer, and the $\mathrm{Hb}$ level was slightly higher in the persistent anemia group than in the improved anemia group.

\section{Cancer-related survival based on Hb trajectory}

The 10-year cancer-related survival curve according to the trajectory groups is shown in Figure 2A. The cumulative incidence by trajectory groups is plotted in Figure 2B. The highest mortality rate occurred for the persistent anemia group. The highest survival rate occurred for the normal $\mathrm{Hb}$ group. Compared with the normal $\mathrm{Hb}$ group, the persisted anemia group had significantly increased mortality in the univariable and multivariable analysis. Nevertheless, the improved anemia group increased mortality in the univariable, but not in the multivariable cox proportional hazards analysis (Table 3). In general, the higher $\mathrm{Hb}$ group had a trend for improved mortality ( $\mathrm{p}$ for trend $<0.001$ ). Although there were no differences in differentiation grade among the $\mathrm{Hb}$ trajectories (Table 2), poor cell differentiation grade was associated with a poor 10-year survival rate. Regarding the impact of the $\mathrm{Hb}$ trajectories on survival, in the univariable and multivariable analysis, mortality began to significantly increase after 1 year for the persisted anemia group (Table 4). In the multivariable analyses, mortality did not significantly increase for the mild anemia, improved anemia and low normal $\mathrm{Hb}$ groups.

\section{DISCUSSION}

The current study revealed there are 5 unique trajectories of $\mathrm{Hb}$ levels during the first year after treatment. The persisted anemia group (initial $\mathrm{Hb}$ level of approximately $10 \mathrm{~g} / \mathrm{dL}$ ) were significantly associated with worst 10-year survival compared with the normal $\mathrm{Hb}$ trajectory groups ( $\mathrm{Hb}$ threshold of approximately $12-14 \mathrm{~g} /$ dL) in breast cancer patients.

It is notable that most $\mathrm{Hb}$ levels declined in the first 6 months after treatment initiation, but the Hb level continued to increase after treatment in the improved anemia trajectory. Despite slightly lower initial Hb levels in the improved anemia group than in the persistent anemia group, the improved anemia group had better long-term survival, with improved survival after 3 years; meanwhile, the mild anemia, low normal $\mathrm{Hb}$, and normal $\mathrm{Hb}$ groups had significantly improved survival after 2 years.

Hypoxia-inducible factor-1 (HIF-1), which is a key molecular response to hypoxia, leads to structural and functional abnormalities in the tumor microvasculature and exacerbates the progress through the pathologic stages [14-17]. HIF-1 contributes to the cancer biology including angiogenesis [18-20], epithelial-mesenchymal transition [21-23], invasion [24, 25], metastasis [26-28], resistance to radiation therapy and chemotherapy [29-31]. Therefore, a recent study showed that HIF-1 $\alpha$ is an indicator of tumor progression, metastasis, and poor patient prognosis. Higher expression of HIF- $1 \alpha$ is correlated with poorer survival in breast cancer patients [32,33]. In contrast, the benefit of higher $\mathrm{Hb}$ levels during treatment might be the result of several factors such as increased blood flow and drug delivery to the tumor or the higher effectiveness of radical-generating agents in the presence of a better oxygen supply, as postulated for radiotherapy [34].

There are several factors that reflect the treatment outcome or survival in breast cancer, including cell differentiation grade, parietal history, ER/PR status, and pathological stage.

Hemoglobin $(\mathrm{Hb})$ levels are related with treatment outcomes and survival in patients with various cancers. However, the anemia criteria of $\mathrm{Hb}$ level differs from literatures. A meta-analysis study by Caro JJ et al. showed anemia is associated with poor survival in cases with lung carcinoma, cervicouterine carcinoma, head and neck carcinoma, prostate carcinoma, lymphoma, and multiple myeloma. However, the cut-off point criteria of anemia varied from $8.5 \mathrm{~g} / \mathrm{dL}$ to $14.0 \mathrm{~g} / \mathrm{dL}$ [2]. Moreover, the $\mathrm{Hb}$ level might change after treatment (chemotherapy, radiation therapy, or surgery) or with different cancer stages. The timing of asses $\mathrm{Hb}$ level associated outcome also vary, including preoperatively, the lowest point during treatment and various time point after therapy. For example, preoperative anemia has proved associated with poor prognosis in breast cancer [13]. The pre-treatment $\mathrm{Hb}$ level (cut-off $12 \mathrm{~g} / \mathrm{dL}$ ) was an independent prognostic factor for overall survival in anal canal cancer patients after radiation-chemotherapy [35]. Pretherapeutic Hb level as an independent useful marker for predicting pathologic tumor response in esophageal squamous cell carcinoma [4].

However, $\mathrm{Hb}$ at the beginning of radiotherapy for supraglottic larynx cancer does not correlate with treatment outcome, but decrease of $\mathrm{Hb}$ during therapy is a strong prognostic factor for treatment failure [3]. Ye et al. confirmed the prognostic importance of hemoglobin level during chemotherapy in gastric cancer patients [5]. $\mathrm{Hb}$ values (cutoff $12.45 \mathrm{~g} / \mathrm{dL}$ ) at the last week of radiation therapy was an independent prognostic factor for overall survival, failure-free survival and loco-regional failurefree survival in nasopharyngeal carcinoma patients [36]. The information from literature was limited to 
Table 2: Baseline Characteristics stratified by Hb trajectory

\begin{tabular}{|c|c|c|c|c|c|c|}
\hline Variable & $\begin{array}{c}\text { Persisted } \\
\text { anemia } \\
(\mathrm{N}=109)\end{array}$ & $\begin{array}{c}\text { Improved } \\
\text { anemia }(\mathrm{N}=93)\end{array}$ & $\begin{array}{l}\text { Mild anemia } \\
\quad(\mathrm{N}=406)\end{array}$ & $\begin{array}{c}\text { Low normal Hb } \\
\quad(\mathrm{N}=\mathbf{8 9 9})\end{array}$ & $\begin{array}{l}\text { Normal Hb } \\
(\mathrm{N}=\mathbf{4 2 4})\end{array}$ & P value \\
\hline Pathologic Stage & & & & & & $<0.001$ \\
\hline 1 & 18.4 & 23.7 & 20.7 & 35.3 & 36.1 & \\
\hline 2 & 40.4 & 44.1 & 45.8 & 40.9 & 47.4 & \\
\hline 3 & 33.0 & 25.8 & 29.3 & 20.8 & 15.1 & \\
\hline 4 & 8.2 & 6.4 & 4.2 & 3.0 & 1.4 & \\
\hline ER+ & 63.9 & 68.5 & 62.7 & 63.9 & 69.5 & 0.22 \\
\hline $\mathrm{PR}+$ & 53.7 & 58.2 & 47.9 & 51.6 & 55.6 & 0.17 \\
\hline $\mathrm{ER}+$ or $\mathrm{PR}+$ & 71.3 & 75.0 & 65.9 & 68.7 & 73.1 & 0.15 \\
\hline HER2 & 37.2 & 32.2 & 41.0 & 34.6 & 33.2 & 0.16 \\
\hline Hormone therapy & 67.0 & 67.7 & 61.6 & 63.3 & 67.9 & 0.29 \\
\hline Chemotherapy & 71.6 & 81.7 & 82.3 & 66.4 & 63.0 & $<0.001$ \\
\hline Surgery & 100.0 & 97.9 & 100.0 & 100.0 & 100.0 & $<0.001$ \\
\hline Parity Hx & 95.2 & 88.6 & 86.7 & 88.3 & 89.5 & 0.18 \\
\hline Age at diagnosis & & & & & & $<0.001$ \\
\hline$<40$ & 11.0 & 8.6 & 13.3 & 14.4 & 10.6 & \\
\hline $40-49$ & 34.9 & 64.5 & 32.0 & 31.7 & 28.8 & \\
\hline $50-59$ & 22.0 & 21.5 & 30.8 & 30.5 & 36.5 & \\
\hline Over60 & 32.1 & 5.4 & 23.9 & 23.4 & 24.1 & \\
\hline $\begin{array}{l}\text { Radiation } \\
\text { therapy }\end{array}$ & 54.1 & 60.2 & 64.0 & 54.0 & 48.1 & $<0.001$ \\
\hline Cell Differentiation & & & & & & 0.30 \\
\hline Well & 10.1 & 10.7 & 8.4 & 10.6 & 11.8 & \\
\hline Moderate & 43.1 & 53.8 & 46.5 & 50.0 & 50.7 & \\
\hline Poor & 46.8 & 35.5 & 45.1 & 39.4 & 37.5 & \\
\hline $\mathrm{Hb}$ at diagnosis & $10.4 \pm 1.3$ & $9.6 \pm 1.4$ & $12.3 \pm 0.9$ & $13.1 \pm 0.7$ & $14.2 \pm 0.6$ & $<0.001$ \\
\hline
\end{tabular}

Data are presented with percentage for categorical data and Mean $\pm \mathrm{SD}$ for continue variable.

Abbreviations: ER+, estrogen receptor positive. $\mathrm{PR}+$, progesterone receptor positive. $\mathrm{ER}+$ or $\mathrm{PR}+$, estrogen or progesterone receptor positive. HER2, human epidermal growth factor receptor 2 positive. Hb, hemoglobin.

analyze the relation between different hemoglobin levels change pattern and survival. The $\mathrm{Hb}$ trajectory can also explain why increasing the $\mathrm{Hb}$ level by transfusion or erythropoietin stimulation did not result in improved outcome for patients with low initial hemoglobin levels in head and neck squamous cell carcinoma [8]. The trend of $\mathrm{Hb}$ trajectory over time can reflect pre-treatment health status and post-treatment response and could be classified into different groups. Therefore, we need a comprehensive view of overall course in $\mathrm{Hb}$ change for future intervention. This study with its longitudinal design and a homogenous population made it possible to investigate patterns of behavioral adjustment since the treatment of breast cancer.

Our data revealed that $\mathrm{Hb}$ level is a reliable indicator for response to therapy; the initial $\mathrm{Hb}$ level after treatment 
A

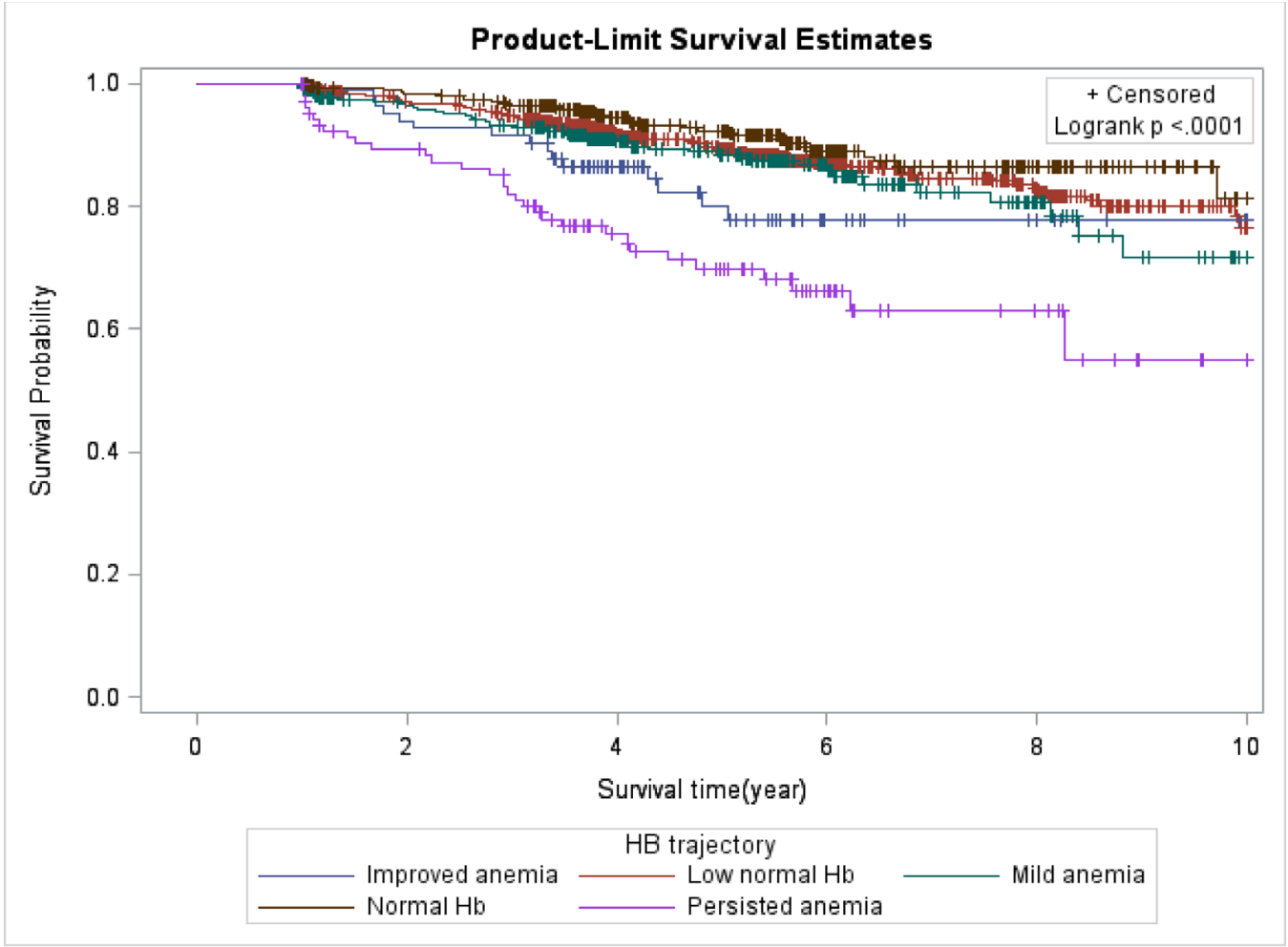

B

Cumulative Incidence Functions

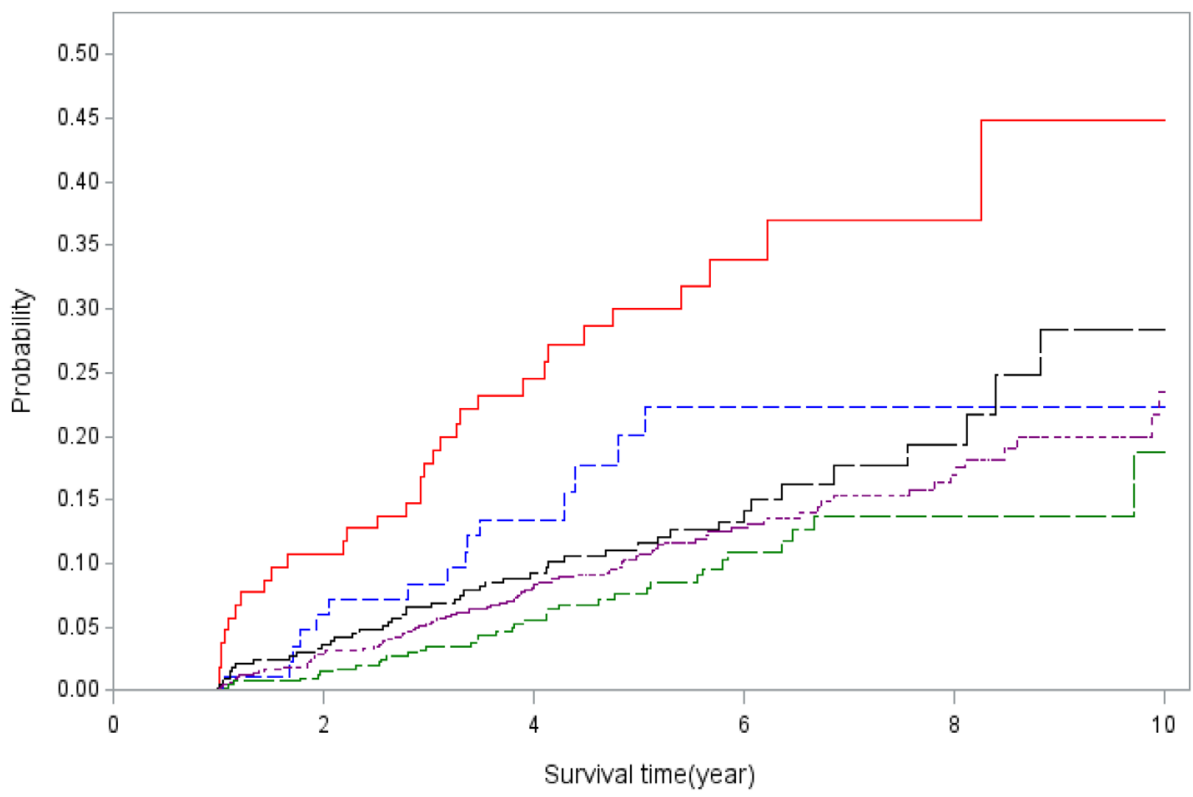

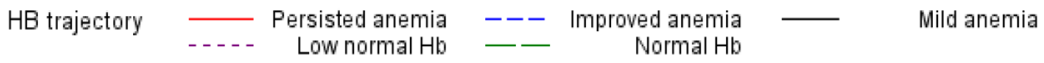

Figure 2: The 10-year survival curve according to the trajectory groups. The highest mortality rate occurred for the persistent anemia group. The highest survival rate occurred for the normal Hb group. Survival curve of Kaplan-Meier analysis by Hb trajectory is shown (2A). The cumulative incidence by trajectory groups is plotted (2B). 
Table 3: Survival analysis of factors associated with overall mortality by cox-proportional hazard model

\begin{tabular}{|c|c|c|c|c|c|}
\hline \multirow{2}{*}{ Variable } & \multicolumn{2}{|c|}{ Univariate } & \multicolumn{2}{|c|}{ Multivariate } & \multirow{2}{*}{$P$ for trend } \\
\hline & HR (95\% C.I) & P value & HR (95\% C.I) & P value & \\
\hline $\mathrm{Hb}$ trajectory & & & & & $<0.001$ \\
\hline Normal $\mathrm{Hb}$ & Ref. & - & Ref. & - & \\
\hline Persisted anemia & $4.17(2.59-6.71)$ & $<0.001$ & $2.19(1.28-3.75)$ & $<0.01$ & \\
\hline Improved anemia & $2.19(1.20-4.00)$ & 0.01 & $1.79(0.91-3.53)$ & 0.09 & \\
\hline Mild anemia & $1.59(1.03-2.45)$ & 0.04 & $1.09(0.68-1.74)$ & 0.73 & \\
\hline Low normal $\mathrm{Hb}$ & $1.34(0.92-1.96)$ & 0.13 & $1.06(0.71-1.60)$ & 0.77 & \\
\hline HER2 & $1.25(0.95-1.66)$ & 0.12 & $0.65(0.48-0.90)$ & $<0.01$ & \\
\hline ER or PR $(+)$ & $0.53(0.41-0.69)$ & $<0.001$ & $0.44(0.31-0.61)$ & $<0.001$ & \\
\hline Parity Hx & $0.53(0.38-0.76)$ & $<0.001$ & $0.56(0.37-0.84)$ & $<0.01$ & \\
\hline Pathologic Stage & & & & & $<0.001$ \\
\hline 1 & Ref. & - & Ref. & - & \\
\hline 2 & $2.10(1.29-3.43)$ & $<0.01$ & $1.95(1.06-3.59)$ & 0.03 & \\
\hline 3 & $6.75(4.22-10.79)$ & $<0.001$ & $6.68(3.58-12.45)$ & $<0.001$ & \\
\hline 4 & $32.59(19.05-55.76)$ & $<0.001$ & $40.41(20.41-80.02)$ & $<0.001$ & \\
\hline Age at diagnosis & & & & & 0.11 \\
\hline$<40$ & Ref. & - & Ref. & - & \\
\hline $40-49$ & $0.65(0.43-1.00)$ & 0.05 & $0.74(0.46-1.19)$ & 0.21 & \\
\hline $50-59$ & $1.06(0.71-1.60)$ & 0.77 & $1.07(0.67-1.71)$ & 0.77 & \\
\hline Over60 & $1.30(0.86-1.96)$ & 0.22 & $1.34(0.82-2.19)$ & 0.25 & \\
\hline Cell Differentiation & & & & & 0.24 \\
\hline Well & Ref. & - & Ref. & - & \\
\hline Moderate & $5.82(2.14-15.79)$ & $<0.001$ & $3.18(1.16-8.71)$ & 0.02 & \\
\hline Poor & $7.81(2.89-21.13)$ & $<0.001$ & $2.96(1.07-8.19)$ & 0.04 & \\
\hline Surgery & $0.16(0.02-1.12)$ & 0.06 & $1.39(0.17-11.53)$ & 0.76 & \\
\hline Chemotherapy & $2.09(1.50-2.92)$ & $<0.001$ & $0.82(0.51-1.31)$ & 0.41 & \\
\hline
\end{tabular}

Abbreviations: $\mathrm{ER}+$, estrogen receptor positive. $\mathrm{PR}+$, progesterone receptor positive. $\mathrm{ER}+$ or $\mathrm{PR}+$, estrogen or progesterone receptor positive. HER2, human epidermal growth factor receptor 2 positive. Hb, hemoglobin.

provided an accurate survival prediction, and the change in $\mathrm{Hb}$ level was associated with the response to treatment. Although the initial $\mathrm{Hb}$ level in the improved anemia group was approximately $9 \mathrm{~g} / \mathrm{dL}$, an increasing trend in $\mathrm{Hb}$ level reflected good response to treatment and resulted in better 10-year survival, compared with the persistent anemia group.

Latent class modeling [37, 38], as used in the current analyses, provides unique insight into $\mathrm{Hb}$ level trajectories during the first 1 year post-treatment period as they relate with 10-year overall survival. The current study confirmed the prognostic importance of different $\mathrm{Hb}$ trajectories as well as a more realistic understanding of the separate trajectory groups. We extended those findings to demonstrate not only that prognosis differs by $\mathrm{Hb}$ level but also that these trajectories reflect survival. Therefore, the trend in the change in $\mathrm{Hb}$ level is more important than the level at a single time during the treatment of breast cancer. This understanding of the effect of a change or timing of the change in $\mathrm{Hb}$ level in various cancer stages might be important for the stratification of survival predictions and future intervention decisions.

Whether preoperative anemia and chemotherapyinduced anemia are both associated with poor prognosis of patients with breast cancer remains to be clarified. In addition, controversy remains regarding adequate 
Table 4: Hazard ratios of the association of $\mathrm{Hb}$ trajectory groups with mortality at different time points

\begin{tabular}{|c|c|c|c|c|c|c|c|c|}
\hline \multirow{3}{*}{ Variable } & \multicolumn{2}{|c|}{2 year } & \multicolumn{2}{|c|}{3 year } & \multicolumn{2}{|c|}{5 year } & \multicolumn{2}{|c|}{10 year } \\
\hline & Univariate & Multivariate & Univariate & Multivariate & Univariate & Multivariate & Univariate & Multivariate \\
\hline & $\begin{array}{c}\text { HR }(95 \% \\
\text { C.I })\end{array}$ & $\begin{array}{c}\text { HR }(95 \% \\
\text { C.I })\end{array}$ & $\begin{array}{c}\text { HR }(95 \% \\
\text { C.I })\end{array}$ & $\begin{array}{c}\text { HR }(95 \% \\
\text { C.I })\end{array}$ & $\begin{array}{c}\text { HR }(95 \% \\
\text { C.I })\end{array}$ & $\begin{array}{c}\text { HR }(95 \% \\
\text { C.I) }\end{array}$ & $\begin{array}{c}\text { HR }(95 \% \\
\text { C.I) }\end{array}$ & $\begin{array}{c}\text { HR }(95 \% \\
\text { C.I })\end{array}$ \\
\hline \multicolumn{9}{|c|}{$\mathrm{Hb}$ trajectory } \\
\hline Normal Hb & Ref. & Ref. & Ref. & Ref. & Ref. & Ref. & Ref. & Ref. \\
\hline $\begin{array}{l}\text { Persisted } \\
\text { anemia }\end{array}$ & $\begin{array}{l}7.8(2.9- \\
21.1)^{* *}\end{array}$ & $\begin{array}{c}3.4(1.2- \\
10.2)^{*}\end{array}$ & $\begin{array}{l}5.6(2.8- \\
11.3)^{* *}\end{array}$ & $2.9(1.3-6.2)^{*}$ & $\begin{array}{l}4.9(2.9- \\
8.3)^{* *}\end{array}$ & $2.4(1.3-4.3)^{*}$ & $\begin{array}{c}4.2(2.6- \\
6.7)^{* *}\end{array}$ & $2.2(1.3-3.8)^{*}$ \\
\hline $\begin{array}{l}\text { Improved } \\
\text { anemia }\end{array}$ & $\begin{array}{c}4.0(1.2- \\
13.2)^{*}\end{array}$ & $2.1(0.5-8.8)$ & $2.5(1.0-6.1)$ & $1.6(0.5-4.5)$ & $\begin{array}{c}2.7(1.4- \\
5.3)^{*}\end{array}$ & $2.0(0.9-4.2)$ & $\begin{array}{c}2.2(1.2- \\
4.0)^{*}\end{array}$ & $1.8(0.9-3.5)$ \\
\hline $\begin{array}{l}\text { Mild } \\
\text { anemia }\end{array}$ & $2.5(0.9-6.6)$ & $1.5(0.6-4.1)$ & $\begin{array}{c}1.9(1.0- \\
3.8)^{*}\end{array}$ & $1.2(0.60-2.5)$ & $1.7(0.9-2.7)$ & $1.0(0.6-1.8)$ & $\begin{array}{c}1.6(1.0- \\
2.5)^{*}\end{array}$ & $1.1(0.7-1.7)$ \\
\hline $\begin{array}{l}\text { Low } \\
\text { normal } \mathrm{Hb}\end{array}$ & $1.9(0.8-4.8)$ & $1.3(0.5-3.4)$ & $1.5(0.8-2.8)$ & $1.1(0.6-2.1)$ & $1.5(0.9-2.3)$ & $1.0(0.6-1.6)$ & $1.3(0.9-2.0)$ & $1.1(0.7-1.6)$ \\
\hline
\end{tabular}

$* \mathrm{P}$ value $<0.05$.

$* * \mathrm{P}$ value $<0.001$

Multivariate: adjusted for age at diagnosis, pathologic stage, cell Differentiation, surgery, chemotherapy, parietal history, estrogen or progesterone receptor positive, human epidermal growth factor receptor 2 positive.

$\mathrm{Hb}$ levels and the benefits of red cell transfusion, erythropoietic stimulating agents, or iron supplement therapy in the treatment of breast cancer-related anemia [5, 39-42]. The current results provide a longterm perspective of different $\mathrm{Hb}$ groups for therapy intervention.

The strength of our study is the use of a trajectory method which has performed in cardiovascular and cerebrovascular disease [43, 44] To our knowledge, this is the first paper about $\mathrm{Hb}$ trajectory related with solid cancer survival. There is also a large number of patients with follow up for twelve years. However, several limitations must be considered when interpreting these findings. Our data only included overall survival but did not provide other prognosis information such as local relapse-free survival, lymph node metastasisfree distance metastasis free survival, and relapsefree survival. Therefore, we were unable to determine whether $\mathrm{Hb}$ level trajectories play the same role in the prediction of these other types of survival. Second, we used a 1-year $\mathrm{Hb}$ level trajectory rather than another time interval because these patients would not have been followed up monthly 1 year after treatment; instead, most of the patients were followed up every 6 months starting1 year after treatment. Third, we were not able to assess the effect of blood transfusion while treatment; we lacked information regarding the need and criteria for transfusion because they differ by patient condition and physician decision. The question of the best timing to increase $\mathrm{Hb}$ levels or the effect for patients with preoperative anemia remains unanswered. Therefore, further studies are needed.
Our findings revealed that different $\mathrm{Hb}$ level trajectories in the first year after treatment predict longterm cancer-related survival. This analysis revealed that improving $\mathrm{Hb}$ levels reelected better cancer-related survival in breast cancer patients. Additional research is needed to examine the utility of specific $\mathrm{Hb}$ trajectories in clinical events, the treatment, and timing of anemia intervention for breast cancer patients.

\section{MATERIALS AND METHODS}

\section{Data source}

This retrospective cohort study enrolled breast cancer patients from the Taichung Veterans General Hospital, a medical center in central Taiwan. All female cases of pathologically proven breast cancer during 20032011 were included.

Age at initial diagnosis of primary breast cancer, pathological stage, Cell differentiation grade, staging at diagnosis based on the tumor/nodes/metastasis staging system of the Union for International Cancer Control, laboratory data during the follow-up, hormone status, parietal history, and subsequent chemo/radiotherapy were recorded. The $\mathrm{Hb}$ level in each month within the 1-year period following diagnosis was recorded. Patients died within 1 year or follow up less than 1 year were excluded. Stage 0 cancer was also excluded. Details of patient selection were shown in Supplementary Figure S2. The cases were followed until 12/31/2014. The primary endpoint was cancer-related death. The study was approved by the institutional review board. 


\section{Statistical analysis}

Continuous variables are reported as the mean \pm standard deviation, and categorical data are reported as frequencies (percentages). Group-based trajectories with a latent class model were used to identify distinct trajectories of $\mathrm{Hb}$. These models were fit using the SAS ProcTraj procedure [14, 15]. Posterior probabilities were used to assign membership to the different trajectory groups. The model fit was assessed using the Bayesian Information Criterion (BIC), and a censored normal model is appropriate for continuous outcomes [16]. The optimal number of trajectory groups was evaluated using the BIC; the number of cases in each trajectory group must exceed $3 \%$ of the total population.

Differences in clinical variables between $\mathrm{Hb}$ trajectories were tested using one-way analysis of variance (ANOVA) for continuous variables and chi-square tests for categorical variables. The survival curve was plotted using the Kaplan-Meier method based on the different $\mathrm{Hb}$ trajectory groups. A Cox-proportional hazard model was used to estimate the impact of the Hb trajectory groups on 10-year overall survival; 2-, 3-, and 5-year survival analyses were also performed to evaluate the impact of $\mathrm{Hb}$ trajectories at different time points. In all the analyses, a two-sided $\mathrm{P}$ value $<0.05$ was considered statistically significant. All the statistical analyses were performed using SAS software (Version 9.4; SAS Institute, Inc., Cary, NC, USA).

\section{ACKNOWLEDGMENTS}

This study was conducted and supported by the Taichung Veterans General Hospital, Taiwan. The study was approved by the local institutional review board. The ethics approval number is VGHTC-SE14070B. With thanks to Cancer Registry database/Taichung Veterans General Hospital for the Support of Clinical data.

\section{CONFLICTS OF INTEREST}

The authors and their families have no commercial associations or sources of support that might pose a conflict of interest. No benefits in any form have been or will be received from a commercial party related directly or indirectly to the subject of this manuscript.

\section{REFERENCES}

1. Ludwig H. Anemia of hematologic malignancies: what are the treatment options? Semin Oncol. 2002; 29:45-54.

2. Caro JJ, Salas M, Ward A, Goss G. Anemia as an independent prognostic factor for survival in patients with cancer: a systemic, quantitative review. Cancer. 2001; 91:2214-2221.
3. Tarnawski R, Skladowski K, Maciejewski B. Prognostic value of hemoglobin concentration in radiotherapy for cancer of supraglottic larynx. Int J Radiat Oncol Biol Phys. 1997; 38:1007-1011.

4. Hamai Y, Hihara J, Taomoto J, Yamakita I, Ibuki Y, Okada M. Hemoglobin level influences tumor response and survival after neoadjuvant chemoradiotherapy for esophageal squamous cell carcinoma. World J Surg. 2014; 38:2046-2051.

5. Ye X, Liu J, Chen Y, Wang N, Lu R. The impact of hemoglobin level and transfusion on the outcomes of chemotherapy in gastric cancer patients. Int J Clin Exp Med. 2015; 8:4228-4235.

6. Montgomery J, Syed MI, Rana I, Singh J, Clark LJ. Hemoglobin monitoring in head and neck cancer patients undergoing radiotherapy. Ann Otol Rhinol Laryngol. 2010; 119:472-475.

7. Spivak JL. The anaemia of cancer: death by a thousand cuts. Nat Rev Cancer. 2005; 5:543-555.

8. Hoff CM. Importance of hemoglobin concentration and its modification for the outcome of head and neck cancer patients treated with radiotherapy. Acta Oncol. 2012; 51:419-432.

9. Barrett-Lee P, Bokemeyer C, Gascon P, Nortier JW, Schneider M, Schrijvers D, Van Belle S, Board EA, Participating C. Management of cancer-related anemia in patients with breast or gynecologic cancer: new insights based on results from the European Cancer Anemia Survey. Oncologist. 2005; 10:743-757.

10. Bottini A, Berruti A, Brizzi MP, Bersiga A, Generali D, Allevi G, Aguggini S, Bolsi G, Bonardi S, Bertoli G, Alquati P, Dogliotti L. Pretreatment haemoglobin levels significantly predict the tumour response to primary chemotherapy in human breast cancer. Br J Cancer. 2003; 89:977-982.

11. Peters-Engl C, Cassik P, Schmidt I, Denison U, Medl M, Pokieser W, Sevelda P. Impact of haemoglobin levels during adjuvant chemotherapy on the survival of patients with primary breast cancer. Acta Oncol. 2005; 44:129-133.

12. Boehm DU, Lebrecht A, Schmidt M, Siggelkow W, Lindner C, Litz A, Ulbrich E, Koelbl H. Prognostic impact of haemoglobin levels in breast cancer. Anticancer Res. 2007; 27:1223-1226

13. Zhang Y, Chen Y, Chen D, Jiang Y, Huang W, Ouyang H, Xing W, Zeng M, Xie X, Zeng W. Impact of preoperative anemia on relapse and survival in breast cancer patients. BMC Cancer. 2014; 14:844.

14. Park SK, Dadak AM, Haase VH, Fontana L, Giaccia AJ, Johnson RS. Hypoxia-induced gene expression occurs solely through the action of hypoxia-inducible factor 1alpha (HIF-1alpha): role of cytoplasmic trapping of HIF-2alpha. Mol Cell Biol. 2003; 23:4959-4971.

15. Wang Y, Li Z, Zhang H, Jin H, Sun L, Dong H, Xu M, Zhao P, Zhang B, Wang J, Pan Y, Liu L. HIF-1alpha and 
HIF-2alpha correlate with migration and invasion in gastric cancer. Cancer Biol Ther. 2010; 10:376-382.

16. Unwith S, Zhao H, Hennah L, Ma D. The potential role of $\mathrm{HIF}$ on tumour progression and dissemination. Int J Cancer. 2015; 136:2491-2503.

17. Bos R, Zhong H, Hanrahan CF, Mommers EC, Semenza GL, Pinedo HM, Abeloff MD, Simons JW, van Diest PJ and van der Wall E. Levels of hypoxia-inducible factor-1 alpha during breast carcinogenesis. J Natl Cancer Inst. 2001; 93:309-314.

18. Zhou J, Schmid T, Schnitzer S, Brune B. Tumor hypoxia and cancer progression. Cancer Lett. 2006; 237:10-21.

19. Liao D, Johnson RS. Hypoxia: a key regulator of angiogenesis in cancer. Cancer metastasis reviews. 2007; 26:281-290.

20. Semenza GL. Targeting Hypoxia-Inducible Factor 1 to Stimulate Tissue Vascularization. Journal of investigative medicine. 2015.

21. Imai T, Horiuchi A, Wang C, Oka K, Ohira S, Nikaido T, Konishi I. Hypoxia attenuates the expression of E-cadherin via up-regulation of SNAIL in ovarian carcinoma cells. Am J Pathol. 2003; 163:1437-1447.

22. Esteban MA, Tran MG, Harten SK, Hill P, Castellanos MC, Chandra A, Raval R, O'Brien T S, Maxwell PH. Regulation of E-cadherin expression by VHL and hypoxia-inducible factor. Cancer Res. 2006; 66:3567-3575.

23. Krishnamachary B, Zagzag D, Nagasawa H, Rainey K, Okuyama H, Baek JH, Semenza GL. Hypoxia-inducible factor-1-dependent repression of E-cadherin in von HippelLindau tumor suppressor-null renal cell carcinoma mediated by TCF3, ZFHX1A, and ZFHX1B. Cancer Res. 2006; $66: 2725-2731$.

24. Sullivan R, Graham CH. Hypoxia-driven selection of the metastatic phenotype. Cancer metastasis reviews. 2007; 26:319-331

25. Krishnamachary B, Semenza GL. Analysis of hypoxiainducible factor 1alpha expression and its effects on invasion and metastasis. Methods in enzymology. 2007; 435:347-354.

26. Erler JT, Bennewith KL, Nicolau M, Dornhofer N, Kong C, Le QT, Chi JT, Jeffrey SS, Giaccia AJ. Lysyl oxidase is essential for hypoxia-induced metastasis. Nature. 2006; 440:1222-1226.

27. Wong CC, Gilkes DM, Zhang $\mathrm{H}$, Chen J, Wei H, Chaturvedi P, Fraley SI, Wong CM, Khoo US, Ng IO, Wirtz D, Semenza GL. Hypoxia-inducible factor 1 is a master regulator of breast cancer metastatic niche formation. Proc Natl Acad Sci U S A. 2011; 108:16369-16374.

28. Zhang H, Wong CC, Wei H, Gilkes DM, Korangath P, Chaturvedi P, Schito L, Chen J, Krishnamachary B, Winnard PT, Jr., Raman V, Zhen L, Mitzner WA, Sukumar S, Semenza GL. HIF-1-dependent expression of angiopoietinlike 4 and L1CAM mediates vascular metastasis of hypoxic breast cancer cells to the lungs. Oncogene. 2012; 31:1757-1770.

29. Moeller BJ, Richardson RA, Dewhirst MW. Hypoxia and radiotherapy: opportunities for improved outcomes in cancer treatment. Cancer metastasis reviews. 2007; 26:241-248.

30. Rohwer N, Cramer T. Hypoxia-mediated drug resistance: novel insights on the functional interaction of HIFs and cell death pathways. Drug resistance updates: reviews and commentaries in antimicrobial and anticancer chemotherapy. 2011; 14:191-201.

31. Semenza GL. Hypoxia-inducible factors: mediators of cancer progression and targets for cancer therapy. Trends in pharmacological sciences. 2012; 33:207-214.

32. Du J, Xu R, Hu Z, Tian Y, Zhu Y, Gu L, Zhou L. PI3K and ERK-induced Rac1 activation mediates hypoxia-induced HIF-1alpha expression in MCF-7 breast cancer cells. PLoS One. 2011; 6:e25213.

33. Vleugel MM, Greijer AE, Shvarts A, van der Groep P, van Berkel M, Aarbodem Y, van Tinteren H, Harris AL, van Diest PJ and van der Wall E. Differential prognostic impact of hypoxia induced and diffuse HIF-1alpha expression in invasive breast cancer. Journal of clinical pathology. 2005; 58:172-177.

34. Haensgen G, Krause U, Becker A, Stadler P, Lautenschlaeger C, Wohlrab W, Rath FW, Molls M, Dunst J. Tumor hypoxia, p53, and prognosis in cervical cancers. Int J Radiat Oncol Biol Phys. 2001; 50:865-872.

35. Oblak I, Cesnjevar M, Anzic M, Hadzic JB, Ermenc AS, Anderluh F, Velenik V, Jeromen A, Korosec P. The impact of anaemia on treatment outcome in patients with squamous cell carcinoma of anal canal and anal margin. Radiol Oncol. 2016; 50:113-120.

36. Zeng Q, Shen LJ, Li S, Chen L, Guo X, Qian CN, Wu PH. The effects of hemoglobin levels and their interactions with cigarette smoking on survival in nasopharyngeal carcinoma patients. Cancer Med. 2016; 5:816-826.

37. Nagin DS, Odgers CL. Group-Based Trajectory Modeling (Nearly) Two Decades Later. J Quant Criminol. 2010; 26:445-453.

38. Nagin DS, Odgers CL. Group-based trajectory modeling in clinical research. Annu Rev Clin Psychol. 2010; 6:109-138.

39. Dangsuwan P, Manchana T. Blood transfusion reduction with intravenous iron in gynecologic cancer patients receiving chemotherapy. Gynecol Oncol. 2010; 116:522-525.

40. Rizzo JD, Brouwers M, Hurley P, Seidenfeld J, Arcasoy MO, Spivak JL, Bennett CL, Bohlius J, Evanchuk D, Goode MJ, Jakubowski AA, Regan DH, Somerfield MR. American Society of Clinical Oncology/American Society of Hematology clinical practice guideline update on the use of epoetin and darbepoetin in adult patients with cancer. $\mathrm{J}$ Clin Oncol. 2010; 28:4996-5010. 
41. Rizzo JD, Somerfield MR, Hagerty KL, Seidenfeld J, Bohlius J, Bennett CL, Cella DF, Djulbegovic B, Goode MJ, Jakubowski AA, Rarick MU, Regan DH, Lichtin AE. Use of epoetin and darbepoetin in patients with cancer: 2007 American Society of Clinical Oncology/American Society of Hematology clinical practice guideline update. J Clin Oncol. 2008; 26:132-149.

42. Hoff CM, Lassen P, Eriksen JG, Hansen HS, Specht L, Overgaard M, Grau C, Johansen J, Bentzen J, Andersen L, Evensen JF, Overgaard J. Does transfusion improve the outcome for HNSCC patients treated with radiotherapy? results from the randomized DAHANCA 5 and 7 trials. Acta Oncol. 2011; 50:1006-1014.

43. Allen NB, Siddique J, Wilkins JT and et al. BLood pressure trajectories in early adulthood and subclinical atherosclerosis in middle age. JAMA. 2014; 311:490-497.

44. Levine DA, Galecki AT, Langa KM, Unverzagt FW, Kabeto MU, Giordani B, Wadley VG. Trajectory of Cognitive Decline After Incident Stroke. JAMA. 2015; 314:41-51. 